\title{
Application of Fuzzy Logic in Automated Lighting System in a University: A Case Study
}

\author{
Renuka Mahajan $^{\mathrm{a}}$
}

${ }^{a}$ Amity University, Noida,U.P. India

\begin{abstract}
Applications based on Fuzzy logic use mathematical reasoning to find the solution to the minutest possible fuzzy set that can range anywhere between 0 and 1 . In this study, the practical implementation of a fuzzy logic controller for automated lighting was presented as a real case of an Indian university to detect the occupancy in the classroom and maintain the luminance level by sensing the daylight in the room. The result of the experiment indicates that the fuzzy logic control method could reduce wasted hours of lighting in unoccupied classrooms.
\end{abstract}

Index Terms: Fuzzy Set, Fuzzy Logic Controller, Occupancy Sensor, lux (lumen per square meter), Lighting Control, Photo Sensor, Energy saving, Reduced Cost.

(C) 2015 Published by MECS Publisher. Selection and/or peer review under responsibility of the Research Association of Modern Education and Computer Science.

\section{Introduction}

Fuzzy Logic was first proposed by Dr. Lofti A. Zadeh in 1965. It is basically a mathematical Fuzzy set, which applies reasoning logic to a particular problem rather than applying the binary logic of either 0 or 1 . Hence, instead of using the exact values that are 0 or 1 (True or False); we can use the fuzzy set values which are between 0-1. We can include those values which are either partially true or partially false e.g. the values which are closer to 0 or closer to 1 . Example of fuzzy set could be values 0.0025 or 0.9837 . These are values which are neither perfectly true nor false. Fuzzy logic therefore allows for the inclusion of vague human assessment in computing problems (Singh et al, 2013).

\subsection{Applications of Fuzzy Logic}

Many areas are researched where the Fuzzy Logic can be applied. It is found to perform exceptionally well in those conditions wherever there is conflict resolution of multiple criteria and thus offers better assessment of

* Corresponding author. Tel.:

E-mail address: 
options. Some applications of fuzzy logic were found in the areas of Design of Fuzzy Temperature Control System (Ruiyan \& Junjie, 2011), Environmental Protection (Saint-Joan and Desachy, 1996), (Ghomshei and Meech, 1999); Fuzzy Computed Torque Controller (Shamsodini et al., 2014), Economy (Hiemstra,1994), (Katagiri and Ishii,1999); Picture Processing (Corridoni,1998); Power Systems (Song and Johns, 1998); Social Sciences(Ragin,2000); Music (Arcos, M'antaras, 2001); Hardware (Kandel and Langholz, 1998); Telecommunications (Qingyang et al 1996), (Carlson et al,1998); Medicine (Barro, and Marin, 2001) (Clarke and Qian,1998); medical data mining (Penaloza and Welch,1997) and medical modelling (DeLeo and Campbell,1995), (Kiseliova and Moraga,2001), e-commerce(Baolu et al, 2011). Fuzzy logic has also been applied in large number commercial products in a variety of fields (Dubois et al, 1997), (Pons et al 2000).

- $\quad$ Fuzzy Logic in Anti Braking System(ABS)

- Fuzzy Logic in optimizing the access network selection in wireless networks.

- Fuzzy Logic in Automated Climate Control in the Air Conditioners

- Fuzzy Logic in water cooler to set the water temperature at a particular temperature.

- Fuzzy Logic in the Temperature Control of Refrigerators.

- Fuzzy Logic in the Automated Lighting Control System.

The previous researchers found that fuzzy logic is useful not only in saving money, but also saving human lives. Consider the case of ABS (Anti Braking System) where on the curved roads, the fuzzy set calculates the degree of the steering turn and relate it with the speed of the vehicle, performing Automated Braking of the vehicle. It thus prevents the vehicle to be drifted along the curvature of the road and keeps the vehicle intact on the road (Bih, 2006). This shows the importance of Fuzzy Logic in today's life style.

Currently, an important application needing immediate attention is that the source of energy originating from fossil energy or fuel is exhausting rapidly. Thus efficient lighting energy usage is an important area for research. The lighting energy efficiency research program propagates the use of fuzzy logic in lighting control method.

Automated Lighting System (ALS) is the concept that uses the various sensors along with fuzzy logic concept to provide Automated Control for illumination in any environment. Lighting controls offer desired luminance at appropriate times while reducing energy use and operating costs of lighting system. The need of different kind of sensor and their usability varies as per the demand and the situation, where it has to be utilized.

The previous research papers by other researchers were centered on power density control of incandescent lamps, which is now rarely used (Panjaitan and Hartoyo, 2011). The goal of research in the domain of automated lighting system is twofold: to conserve the energy and reduce the overall cost in the form of lesser electricity bills, thereby providing an automated environment in the area it is deployed. This concept has been widely used and well accepted by various multinational corporations (like Wipro, Tata consultancy service, Sun life Insurance, Infosys) as the part of regulation and obligation to reduce their carbon foot print and reducing the overall energy consumption. On deeper study, it has been found out that it is absolutely beneficial not only in the MNC's but also in buildings, highway tunnels, homes, schools and universities. This research demonstrates its efficiency in a case study at an Indian university. During daytime in a university, it was observed that majority students leave the class rooms without switching off the lights in the classes and those lights remains on throughout the day until someone individually shuts them off. The use of the ALS can also be seen important when there are only few students in the class, occupying only first two rows. However, the lights remain on for the entire class, thus causing extra burden on electricity bill and also a lot of electricity wastage.

This gave us the motivation to research on a new application automated lighting system using fuzzy logic. In this paper, fuzzy logic is proposed as the control method for a room lighting system. I organize this paper as follows: I describe hardware requirements in Section 2. I discuss the methodology in Section 3. I explain the simulation in section 4 and simulation results in Section 5. I provide our concluding remarks in Section 6. Pointers for future work are given in Section 7. 


\section{Hardware Requirements}

The hardware required for implementing the system is the following

- Occupancy Sensors

As the name suggests the sensors are the device that measures/sense the physical property and respond to it accordingly. The type of sensors used here are the following

- Passive Infrared Sensor

It measures the infrared red light radiating from the object and records that information to act on it as per the requirement. All object emit infrared heat signatures which are not seen by the human eye these are well read by the PIR sensor as it measures all the heat signatures above 0 degree. The price for a basic PIR sensor ranges from Rs. 500-2000 for a single sensor.

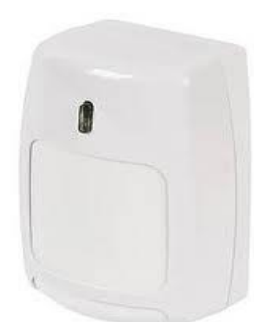

\section{A BASIC PASSIVE INFRARED SENSOR}

- Ultrasonic Sensor

Ultrasonic sensors send high frequency waves in the environment just like the sonar of the submarine and record the waves that come back to the sensor. As the wave hits an object the irregularities in the pattern are made thus triggering the sensor of occupancy in the room and lights are turned on, the lights are turned off when the wave patterns become static again. The price for the Ultrasonic sensor ranges from Rs. 800-3000 for a single sensor.

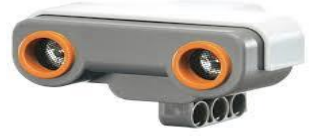

\section{A BASIC ULTRASONIC SENSOR}

\section{○ Light Sensors}

They are used to sense the light in the environment as how much Lux is maintained in the environment from both indoor and outdoor lighting in a particular room, lecture hall or hallway. 


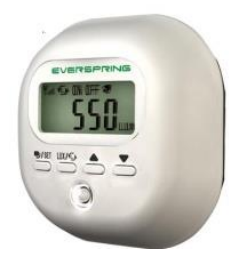

○ Wire Cabling

For the system to work there is no need of using any additional wiring the existing wiring is self-sufficient for the system to work with an additional 5-10 meters for connecting the controller to the sensor and to the electric box.

\section{○ Electric Control Unit}

The Electric Control Unit or the ECU is connected to the sensors this unit receives the sensor signals and uses it to change the electric relay on or off thus controlling the lighting of the environment.

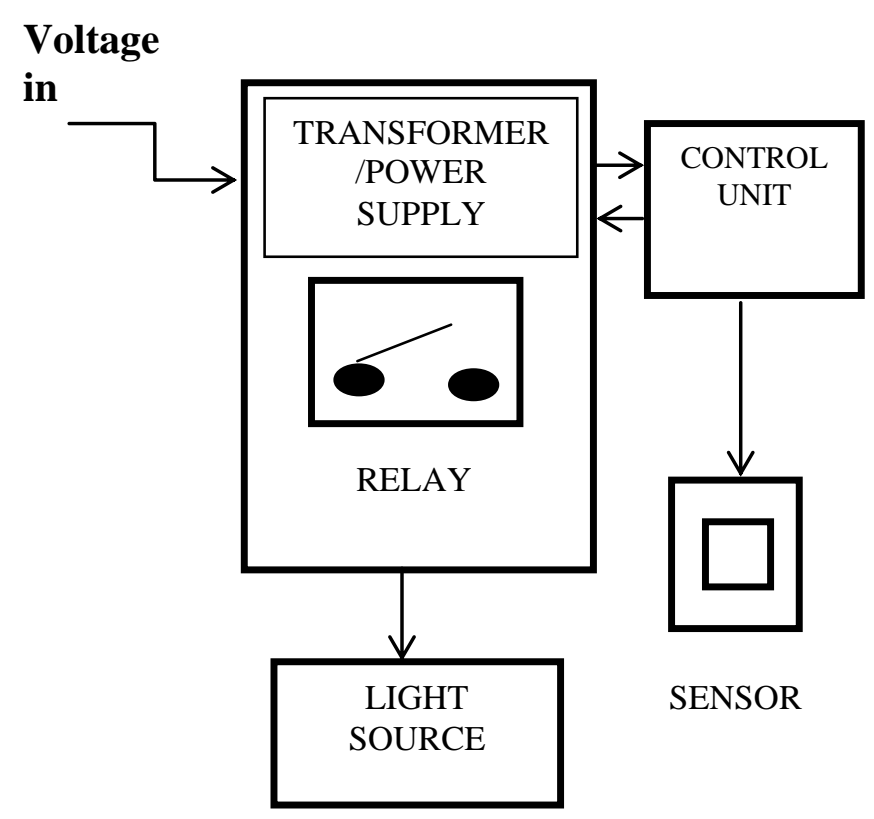

Fig. 1. Hardware Block Diagram 
Table 1. Current Illuminance Measurement (with and without sensors)

\begin{tabular}{|c|c|c|c|}
\hline R.\# & Private Institution (Noida) & W/o sensors & With sensors \\
\hline 1. & Cost of electricity (per kw) & 6.75 & 6.75 \\
\hline 2. & $\begin{array}{l}\text { Operational hours of passage tube } \\
\text { lights }\end{array}$ & 8 & 5 \\
\hline 3. & $\begin{array}{l}\text { Power capacity of tube light (in } \\
\text { watts) }\end{array}$ & 40 & 40 \\
\hline 4. & Total consumption (in watts) & 320 & 200 \\
\hline 5. & Number of days & 22 & 22 \\
\hline 6. & $\begin{array}{l}\text { Total power used by one tube light } \\
\text { (in kw) }\end{array}$ & 14.54 & 9.09 \\
\hline 7. & Amount paid (per month) & 98.14 & 61.35 \\
\hline 8. & $\begin{array}{l}\text { Savings per month per } 1 \text { tube light } \\
\text { (in Rs.) }\end{array}$ & & 36.75 \\
\hline
\end{tabular}

\section{Methodology}

The analysis was conducted on a real world data set in a lecture hall I1- 301 of Indian University, with capacity of 50 seats, during the time period $1^{\text {st }}$ February 2014 to $28^{\text {th }}$ February 2014 . To perform the design process, some parameters and measurement method were done as follows:-

\section{i. Choosing the Sensor}

Occupancy sensors are of two types which are PIR sensor or the Ultrasonic sensor. PIR sensor uses the changes in the infrared heat signature of an object; the motion is detected when the moving person moves thus changing the heat signature of the area and thus lights are turned on. The sensor must have unobstructed view in the case of PIR sensor.

Area scanned also plays an important role as farther the object the lesser is the sensitivity of the sensor. They are well suited for open areas such as Conference halls. Another advantage of PIR sensors are they are cheap and have low false triggering.

The Ultrasonic sensor, emit inaudible sound sensor and read the reflection. They can see around the obstruction and are best for the areas with cabinet shelves and restroom as well as areas where 360 degree coverage is required. Thus they have zero coverage gaps. Their drawbacks are more prone to false signaling, interference with the other ultrasonic device such as hearing aids and they are costly compared to the PIR sensor by about $20-30 \%$.

We can use a hybrid technology (Energy Observer, 2007) where the occupancy sensors use both passive infrared and ultrasonic technology. We can overcome the disadvantages of the sensors. It will make the overall system a bit costlier but the efficiency of the system is greatly increased thus controlling lighting and saving cost in almost every place.

\section{ii. Sensor Placement and Sensitivity}

It can be treated as the most crucial part of the whole system specially when using a hybrid system. It is of utmost importance which sensor to be used where and how to make the system work at full efficiency thus making sensor placement the most important part. Sensitivity of the sensor is also an important part where as too sensitive system will cause false triggering by a passerby in the hall way and those sensors won't save sufficient amount of electricity. Too low sensor sensitivity will cause the light to shut off when the movements 
are low especially during the time of presentations in the conference hall. Thus choosing the proper place and Sensitivity is very important.

\section{iii. Efficiency}

Efficiency is "the capability of the system is to provide the appropriate performance relative to the amount of resources used, under the stated condition". To measure the efficiency of the system we must understand the current scenario without the occupancy sensors. The following might explain it.

The Table 1 explains the scenario quite easily. Considering the without sensor case, the cost of electricity for the private institution in the Noida are Rs.6.75 (http://www.noidapower.com/Download/Tariff.pdf). In a particular university the total time a single tube light runs is 8 hours in a day in a lecture hall I1- 301 with capacity of 50 seats. Hence, for a 40 watt tube light consumes 320 watt per day as monitored on 1st February 2014. Now multiplying it with the total weekdays in a month the amount is equal to 14.54 Kilowatt which gives a sum of Rs.98.14 per month expenditure from one single tube light.

Now with the sensor the total running time for the tube light is reduced to 5 hours which gives an overall expenditure of Rs.61.35 per month thus saving Rs.36.75 from one single light. Multiplying it with an average of 7 tube lights in a classroom and 7 fans (if they are linked to the system too) then this saving will be very large and this calculation is of one single room, not to mention there are hundreds of room in a university. Thus the efficiency of the system is well ascertained from the fact that the saving are much more than the initial capital employed in the system thus making it a great success if deployed in a university and the return on investment (ROI) can be seen from a time period of 5-14 months from the date of system deployment.

\section{Simulation}

The use of fuzzy logic in the system is at the control unit area where the IF-Then logic is applied on the input from the sensors in the system. The use of fuzzy logic in the system can be in two different ways.

Lighting Control- It is for the Lighting in the system to be turned on or off as per the recording of the sensor in the system.

An Algorithm for the system with Lighting Control (Kharb \& Mahajan, 2014)

If (sensor $=$ true $)$

Then

Lights $=$ On

Else

Lights $=$ off

Lighting control works only for the lighting as the sensor will only judge if there is any presence of a human in the environment it is sensing and if there is then lights are turned on.

Luminance Control- Fuzzy logic can also help maintain the luminance level in the class room or an area by sensing the daylight in the room and maintaining the light in that room accordingly. Thus results in saving a lot of electricity.

An adaptive algorithm for the luminance control would be

If Sensor $=$ True and Lux $<400$

Then

Increase the Output

Else

If Sensor $=$ True and lux $>400$

Then 
Decrease the output maintain Lux

Luminance control works with help of lighting control. It cannot shut light off or on but it help in maintaining the light in the area it is employed by changing the output of the sensors accordingly (Miki et al, 2004).

The system will be very beneficial if with the lighting control the luminance control is also added in the system. According to a study (Lighting Development, 2012) the maintained level of luminance required in a lecture hall is about 400lux so to maintain the system which can ensure that the level is maintained and if the level goes up then reducing the lights or lowering the output of the lights can help in saving electricity.

The luminance of the room can be controlled with the same controller as the lighting controller with an added Microprocessor (Bangali and Shaligram, 2012) which acts as the intermediary between the both systems to provide the optimum result.

\section{Simulation Results}

Table 2. Fuzzy Rules for Automated Lighting Control System

Input $x 1$

\begin{tabular}{|l|l|l|l|l|l|}
\hline Input X2 & Very low & Low & Middle & High & Very high \\
\hline Low & Very high & High & High & High & Middle \\
\hline Middle & High & Middle & Middle & Middle & Low \\
\hline High & Middle & Low & Low & Low & Very low \\
\hline
\end{tabular}

The above table 2 shows the fuzzy rules (Panjaitan and Hartoyo, 2011) for the luminance control which is used by the fuzzy controller, where $\mathrm{x} 1$ denotes the outdoor light sensor entering the room and $\mathrm{x} 2$ denotes the indoor light sensor. The membership function (Panjaitan and Hartoyo, 2011) will also help in determining the luminance of the room. These rules can be used to design the system which receives the input light and maintain a proper and appropriate lighting in the environment.

Maintaining the light according to the occupancy and presence detection and the lux will help reduce the electricity charges as well as the conserving the energy. According to other studies as in (Tatum and PE, 2011) (Panjaitan and Hartoyo, 2011) (Hartoyo and Panjaitan, 2012) (Kiyanfar et al, 2012), the overall energy have been saved for all the classrooms.

\section{Conclusions}

The simulated results confirmed the objectives of the study. It can control the light switches by turning them on or off as per the human presence, in the vicinity of the system. It can also help in the maintaining the light intensity with the use of the light sensors that can judge the lux of the room and adapt the fuzzy controller accordingly to provide the output to the lamps and tube light accordingly.

It is now be concluded that Fuzzy Logic and its application in the public places like universities, in the form of automated lighting control system, will result in both energy as well cost saving.

The results were quite encouraging compared to the conventional lighting system. It is recommended that such system should be implemented in every university to increase system's efficiency. It is particularly useful in such a scenario because the number of footfalls in a university is generally very large.

\section{Future Work}

In future, the lighting of the lecture halls should be adapted automatically to different levels for different activities like lectures, for data or video viewing on overhead projectors and for videoconferencing. While lecturers should continue to concentrate on delivery, there should be change in the lighting levels by tuning the 
equipment as required. This lighting control should default to the original settings when switched off.

\section{References}

[1] Arcos J. L. and M'antaras R. L 'opez de 2001, "An interactive case-based reasoning approach for generating expressive music," Applied Intelligence, no. 14, 115-129.

[2] Bangali J. A., Shaligram A. D. 2012, Energy Efficient Lighting Control System Design for Corridor Illumination. International Journal of Scientific and Engineering Research, 3, No. 4.

[3] Barro S. and Marin R. 2001. "Fuzzy logic in medicine," in Springer Series "Studies on Fuzziness and Soft Computing. Physica-Verlag.

[4] Baolu W., Feng D., Jingxu L. 2011, "C2C E-commerce Risk Assessment Based on AHP and Fuzzy Comprehensive Evaluation", International Journal of Engineering and Manufacturing(IJEM),1,1. ISSN: 2305-3631.

[5] Bih, J. 2006. Paradigm shift-an introduction to fuzzy logic. IEEE Potentials, 25, No. 1, 6-10.

[6] Carlson C. M. F., Tavares H. M. F., and Formigoni J. R. F. 1998 "Parametric mixed linear programming with fuzzy numbers and an application to telecommunications networks planning," in Proceedings. SBT/IEEE International Telecommunications Symposium ITS'98, 1, 323-328.

[7] Clarke L. P. and Qian W. 1998 "Fuzzy-logic adaptive neural networks for nuclear medicine image restorations," in Proceedings of the 20th Annual International Conference of the IEEE Engineering in Medicine and Biology Society 3, IEEE-CS-Press, Ed. , 1363-1366.

[8] Corridoni J. M., del Bimbo A., and Pala P. 1998 "Retrieval of paintings using effects induced by color features," in Proc. IEEE International Workshop on Content-Based Access of Image and Video Database, IEEE-CS-Press, Ed., 1998, 2-11.

[9] DeLeo J. M. and Campbell G. 1995. "Biomedical applications of uncertainty modelling and analysis with fuzzy receiver operating characteristic methodology," in Proc. Of the 3rd Int. Symposium on Uncertainty Modelling and Analysis ISUMA - NAFIPS '95, IEEE-CS-Press, Ed., 192-197.

[10] Dubois D., Prade H., and Yager R. 1997. Eds., Fuzzy Information Engineering. A guided tour of applications. N.Y.: John Wiley and Sons.

[11] Electricity Tariff rates for Noida region Uttar Pradesh India, http://www.noidapower.com/Download/Tariff.pdf, for the financial year 2013-2014.

[12] Ghomshei M. M. and Meech J. A. 1999, "Towards a better understanding of fuzzy sets applied to environmental science," in Proc. 2nd Int'l Conference on Intelligent Processing and Manufacturing of Materials IPMM'99, 519-526.

[13] Hartoyo A and Panjaitan S. D. 2011," A Lighting Control System in Buildings based on Fuzzy Logic" TELKOMNIKA, .9, No.3, 423-432.

[14] Hiemstra Y. 1994, "A stock market forecasting support system based on fuzzy logic," inProc. TwentySeventh Hawaii International Conference on System Sciences, III: Information Systems: Decision Support and Knowledge-Based Systems, 281-287.

[15] Kandel A. and Langholz G. 1998. Eds., Fuzzy Hardware. Architectures and Applications. Boston: Kluwer.

[16] Katagiri H. and Ishii H. 1999, "Fuzzy portfolio selection problem," in Proc. IEEE International Conference on Systems, Man, and Cybernetics 1999. IEEE SMC ‘99, 3, IEEE-CS-Press, 973-978.

[17] Kharb V, Mahajan R. 2014. Fuzzy Logic and Automated Lighted System. International Conference on Reliability Infocom Technologies and Optimization. Poster Presentation.

[18] Kiseliova T. and Moraga C. 2001. "On incorporation of time in medical expert systems," Tatra Mountains Mathematical Publications, No. 21, 19-30.

[19] Kiyanfar M., Lotfibonab M., Lotfibonab P. 2012. "Automated Room-Light Controller Using Fuzzy Logic" Journal of Artificial Intelligence in Electrical Engineering, 1, No. 2.

[20] Lighting Development, Lighting Development Adoption and Compliance Guide 2012 United States 
Department of Energy.

[21] Miki M., Hiroyasu T., Imazoto K. 2004, Proposal of Intelligent Lighting System, and Verification of Control Method Effectiveness. Computational and Information Science - CIS, 2004.

[22] Penaloza M.A. and Welch R.M. 1997. "Infectious disease and climate change: a fuzzy database management system approach," in IEEE Int. Geoscience and Remote Sensing, IGARSS '97. Remote Sensing - A Scientific Vision for Sustainable Development, 4. IEEE-CS-Press, 1950-1952.

[23] Pons O. and Vila M.A. and Kacprzyk J. 2000, Ed., Knowledge management in fuzzy databases. Heidelberg: Springer.

[24] Qingyang $\mathrm{Hu}$ and Petr D. W. and Braun C. 1996. "Self-tuning fuzzy traffic rate control for ATM networks," in Proc. IEEE International Conference on Communications, ICC 96. Converging Technologies for Tomorrow's Applications, 1. IEEE-CS-Press, 424-428.

[25] Quyen H. A., Le T. T. T., Le T. N., Pham T. M. T., Combining the Daylight and Artificial Light Based on Fuzzy Logic 2014. AETA 2013: Recent Advances in Electrical Engineering and Related Sciences, Lecture Notes in Electrical Engineering, 282, 93-102.

[26] Ragin Ch. 2000. Fuzzy-sets Social Science, ISBN 0226702774.

[27] Ruiyan N., Junjie R. 2011 "Design of Fuzzy Temperature Control System Based on LabVIEW", International Journal of Engineering and Manufacturing, 1, 6.

[28] Shamsodini M., Piltan F., Rahbar S., Pooladi E., Davarpanah H. (2014) "Design New PID like Fuzzy CTC Controller: Applied to Spherical Motor" International Journal of Modern Education and Computer Science,6, 5 DOI: 10.5815/ijmecs.

[29] Saint-Joan D. and Desachy J.1996, "A raster-based fuzzy expert system for forestry evolution," in Proc. Geoscience and Remote Sensing Symposium, IGARSS '96. Remote Sensing for a Sustainable Future. IEEE-CS-Press, 1996.

[30] Singh H., Gupta M. M., Meitzler T., Hou Z .G., Garg K. K., Solo A. M. G. and Zadeh L. A. 2013. RealLife Applications of Fuzzy Logic. Advances in Fuzzy Systems, Hindawi Publishing Corporation, Volume 2013, Article ID 581879, 3 pages.

[31] Song Y.H. and Johns A.T., "Application of Fuzzy Logic in Power Systems, Part 2: Comparison and Integration with Expert Systems, Neural Networks and Genetic Algorithms", IEE Power Engineering Journal, .12, No.4, 185-190, 1998.

[32] Tatum M. C., PE M. 2011. Performance of an Automatic Lighting Control System - A Case Study, 47th ASC Annual International Conference Proceedings.

[33] The Energy Observer. 2007. Energy Office, Michigan Department of Labor and Economic Growth, Occupancy sensors for lighting control.

\section{Author's Profile}

Renuka Mahajan is an assistant professor of Computer Science at Amity University, Uttar Pradesh. She is currently pursuing her $\mathrm{PhD}$. (CS\&E) from AUUP. Her current research interests include educational data mining, recommender systems and e-CRM. She has published in the Springer Journal EAIT, Inderscience IJIL and IJLEG, IJEEEE and few other professional conference proceedings.

How to cite this paper: Renuka Mahajan,"Application of Fuzzy Logic in Automated Lighting System in a University: A Case Study", IJEM, vol.5, no.3, pp.11-19, 2015.DOI: 10.5815/ijem.2015.03.02 